\title{
Equity in the Delivery of Health Care in Taiwan
}

\author{
Hsiu-Jen Jennifer Yeh* \\ Chin-Shyan Chen** \\ Tsai-Ching Liu***
}

Tokyo, March 1-3, 2003

Email: Yeh@sw.ccu.edu.tw

Paper prepared for presentation at the Conference of

The Research Committee on Social Stratification (RC 28) of

The International Sociological Association

* Department of Social Welfare, National Chung Cheng University, Taiwan

** Department of Economics, National Taipei University, Taiwan

*** Department of Public Finance, National Taipei University, Taiwan 


\title{
Equity in the Delivery of Health Care in Taiwan
}

\author{
Hsiu-Jen Jennifer Yeh \\ Chin-Shyan Chen \\ Tsai-Ching Liu
}

\begin{abstract}
This study examines the extent of equity in the delivery of health care in Taiwan; in addition, this study investigates the stratification of health care utilization across different social groups. The data analyzed come from 1999 to 2001 matched data of tax returns files (collected by Ministry of Treasury) and health care utilization files (collected by Bureau of National Health Insurance).

The analysis of this study finds that the distribution of total medical expenditure is progressive with income; however, the magnitude is moderate over the three years examined. Total medical expenditure varies with family size, with two-person families having the highest average expenditure and frequencies of utilization, followed by seven-person and eight-person families. Except for the youngest age group, age has strong positive relation with total medical expenditure, especially for the two oldest age groups.

In terms of insurance status, this study finds low-income families (families on social assistance) have the highest total medical expenditure. Women tend to have lower total medical expenditure, but higher frequencies of health care utilization compared to men. Among the six regions in Taiwan, people in the eastern part of Taiwan have the highest total medical expenditure. As expected, people living in remote areas and those with catastrophic disease have much higher health care utilization in terms of expenditure and frequency than those living in non-remote areas and those not having catastrophic disease, respectively.
\end{abstract}




\title{
Equity in the Delivery of Health Care in Taiwan
}

\author{
Hsiu-Jen Jennifer Yeh \\ Chin-Shyan Chen \\ Tsai-Ching Liu
}

\section{INTRODUCTION}

Traditionally health care use can be treated as one of the means to the ends of health promotion. In this sense, inequalities in health care are no less important than inequalities in health. In the past a huge body of evidence has indicated substantial health inequalities across socioeconomic strata. Specifically health inequalities by education (Valkonen, 1989; Ross and Wu, 1995; House et al., 1994); by occupation (Siegrist, 1987; Kunst and Mackenbach, 1994; Rahkonen, Arber, and Lahelma, 1995; Glendinning, Hendry, and Shucksmith, 1995; Sundquist and Johansson, 1997); and by income (Wilkinson, 1986; Terris, 1992; O’Connell and Propper, 1990; House et al., 1994). In spite of substantial research in health inequalities, relatively less research has examined the extent of health care inequalities across different socioeconomic strata, and of the equity of health care delivery on the macro level.

Before the establishment of National Health Insurance, approximately half of the total population in Taiwan was not covered by health insurance. The implementation of National Health Insurance since 1995 has dramatically expanded the population coverage of health care protection. Nevertheless, comprehensive coverage is not a sufficient condition to guarantee the delivery of adequate health care. Currently, government subsidizes insurance premium to seven categories of the insured, the major objective is to help the socially disadvantaged groups reduce their financial 
burdens when facing medical indigence. However, premium subsidies are not the only way to help those socially disadvantaged. Another way to providing sufficient health care to the underprivileged is to enhance the delivery of health care.

This study assesses equity in the delivery of health care in Taiwan. The data analyzed in this study come from 1999 to 2001's health care utilization files, which have been collected by Bureau of National Health Insurance (BNHI). Since BNHI does not collect the information of personal income, the three years of health care utilization files have been matched-through social security ID number, with tax returns files provided by the Ministry of Treasury. This study compares three years of health care utilization files from BNHI in order to detect trends in the impacts of National Health Insurance on the extent of equity in health care delivery.

This study investigates two research questions:

To assess equity in the delivery of health care in Taiwan from a macro perspective. Specifically, this study computes index of inequity for one major component of health care provision; namely, medical expenditure. The index of inequity is similar to Gini index for income distribution. It is a good indicator of inequity in that it can accurately measure the degree of inequity in the delivery of health care.

To examine whether delivery of health care in Taiwan under the National Health Insurance scheme differs by different socioeconomic groups. Specifically, this study examines stratification of health care delivery by age, sex, income, insurance status, 
family size, region, rurality, and catastrophic disease status. Such investigation has crucial policy implications for the allocation of health care resource under the National Health Insurance scheme.

\section{THEORETICAL FRAMEWORK}

\section{Current Status of NHI}

It has been seven years since the establishment of Taiwan's National Health Insurance in 1995, the most important accomplishment of NHI is that it has substantially removed the financial barriers of health care access and provided basic social protection of health care for the general public. However, since 1998 the financing of NHI has encountered deficit problems. Factors contribute to such deficits include the continuing rise of medical expenditure that accompanied with the increase of health care use; and the limited growth of premium revenue.

Faced with the NHI financial crisis, the health care authorities in Taiwan have put into action several health care policy reforms. Since 1998, NHI started to enforce global budget for dental care, Chinese medicine, and western medicine; to increase co-payment for medicine and medical examination in order to contain the growth of medical expenditure and to prevent the abuse of health care resource. Nevertheless, how to balance between the containment of health care cost and the social right of health care protection is one of the major concerns of Taiwan's health care authorities.

\section{Conception of Equity}

Generally, equity and efficiency are the two common goals of all kinds of health care systems, however, consensus about equity has been more difficult to achieve than 
for consensus about efficiency. Past research has defined equity from two different perspectives, one is based on egalitarian approach, and the other is based on libertarian approach. Egalitarian approach allocates medical resource according to medical need, considers health care as one of the entitlements of civil right. Therefore access of health care should not be constrained by individual's income or assets; and the major concern of this approach is equality of health care.

On the other hand, libertarian approach emphasizes personal preferences and plural interests, the attainment of health care is considered as part of the system of social rewards. Therefore it has been taken as appropriate that individual with different ability to pay enjoys different level of health care; and the major concern of this approach is that health care system should only provide minimum health care for the general public (Le Grand and Robinson, 1984; Maynard and Williams, 1984; Culyer, 1980; Wagstaff, van Doorslaer, and Paci, 1994; Yeh et al, 1998a).

\section{Principle and Definition of Equity}

Inequalities of health care are not the same as inequities of health care. This study adopts the egalitarian approach in defining equity. Equity of health care allows distribution of health care favoring the poor. Specifically, the equity principle of health care implies equal treatment for equal need. Traditionally, equity in the delivery of health care has been measured in the following procedures (van Doorslaer, 1993; Wagstaff et al, 1994; van Doorslaer et al, 2000). First, to calculate illness

concentration index $\left(\mathrm{C}^{\mathrm{ill}}\right)$, where each individual has been ranked by income on the horizontal axis, with the vertical axis indicating the cumulative percentage of population illness status. Second, to calculate expenditure concentration index $\left(C^{\exp }\right)$, 
where each individual has been ranked by income on the horizontal axis, with the vertical axis indicating the cumulative percentage of population medical expenditure. Third, to calculate inequity index of health care $(H I)$, where $H I=\mathrm{C}^{\mathrm{exp}}-\mathrm{C}^{\text {ill }}$. If $H I$ is positive, it means inequity of health care favoring the rich; on the other hand, if $H I$ is negative, it means inequity of health care favoring the poor. If $H I$ is zero, it means equity of health care to the advantage of the rich as well as the poor.

\section{Past Research about Equity in the Delivery of Health Care}

Le Grand (1978) analyzed 1972 U.K. General Household Survey, and found that although the medical expenditure share of lower occupation class is higher than that of upper class, the expenditure share of lower class is still less than its share of medical need of total population. On the other hand, although upper class' share of medical expenditure is less than that of lower class, it is higher than its share of medical need of the total population.

Hurst (1985) analyzed 1976 U.K. General Household Survey, his finding was similar to Le Grand's study, that the lower the income deciles, the larger the gap between the share of medical need and the share of medical expenditure, with the share of need greater than the share of expenditure. Such gap gradually decreases as income level increases and up till the ninth and tenth deciles, such gap reverses with the share of expenditure exceeds the share of need.

Wagstaff et al (1994) compared the extent of equity in the delivery of health care for U.K., the Netherlands, and Italy, they calculated concentration index of medical expenditure and illness, and $H I$ inequity index for each country and found that all 
three countries have negative concentration index for both illness and medical expenditure. This implies that the poor are less healthy and use more health care than the rich. The $H I$ value for the three countries are all positive, which means that health care utilization is more favorable to the rich, with Italy has the highest $H I(0.118)$, followed by the Netherlands (0.038), and U.K. (0.014).

Lairson et al (1995) examined the extent of equity in the delivery of health care in Australia, he standardized medical expenditure by age, sex and health status, then calculated the concentration index for standardized expenditure, which is another way of calculating $H I$ value. Lairson et al found that when using self-evaluated health status measure in calculating $H I$, the $H I$ value for total medical expenditure, outpatient expenditure, and inpatient expenditure are all positive (between 0.05 and 0.10 ), meaning that distribution of health care utilization is more favorable to the rich. On the other hand, when using catastrophic or chronic disease status in calculating $H I$, the $H I$ value for total medical expenditure, outpatient expenditure, and inpatient expenditure are virtually negative (between 0 and -0.05 ), meaning that distribution of health care utilization is more favorable to the poor.

Since the establishment of NHI, there has been some research engaged in the investigation of the differential of health care utilization across social groups (Cheng and Chiang, 1997; 1998; Yeh et al, 1998b), and in the extent of equity in the delivery of health care (Lo, 1998; Cheng et al 1999; Tsay, 1999; Yeh, 1999; Hsiao and Lu, 2000; Cheng et al 2002; Tsay and Chou, 2002). Given the limited space for literature review, the following discussion has selected some of the above research for review. 
Yeh et al (1998b) analyzed the data from 1984 to 1994 Survey of Family Income and Expenditure (SFIE), and found that the first to the third income deciles have average medical expenditure higher than the grand average (across all households) medical expenditure. This study also found $U$ shape of the distribution of medical expenditure across 10 deciles, that is, the two extremes of the income deciles had relatively higher medical expenditure. In addition, when examining the ratio of medical expenditure to total household expenditure, the first three income deciles have its ratio exceeding the average ratio across all households, and this pattern has been relatively stable from 1984 to 1994 .

Yeh (1999) analyzed 1997 SFIE survey data, and the results indicated that people with the least education used relatively higher outpatient and inpatient care in terms of frequencies and hospitalization stays. The pattern is similar with regard to occupation, that is, the lower status of the occupation, the higher level of health care use. The concentration index for outpatient visit and inpatient days were both regressive, however, the extent of regressivity is greater for outpatient care. The concentration index for total medical expenditure, outpatient expenditure, and inpatient expenditure are all progressive, part of the reason that cause such pattern is due to income's positive effect on medical expenditure.

Cheng et al (1999) analyzed 25,000 households' data, which were sampled from the 124, 874 households data file collected by BNHI. The 25,000 households data have been adjusted to the household type structure of 1996 SFIE survey data. Cheng et al (1999) found that except for outpatient expenditure, total medical expenditure and inpatient expenditure are both relatively higher among low-income deciles. For 
example, the highest two income deciles' inpatient expenditure constituted only $83 \%$ of that expenditure for the two lowest income deciles. In addition, the concentration index for household medical expenditure is 0.0319 , meaning that rich people have relatively higher medical expenditure than the poor.

Cheng et al (2002) updated the 25,000 households data from 1996 to 2000, their study found that there has been little change over time regarding the distribution of health care utilization. When examining total medical expenditure, there were no substantial differential across income deciles. However, higher income deciles tend to use more outpatient care (expenditure), whereas lower income deciles tend to use more inpatient care (expenditure). Moreover, the gap of co-payment between high and low income deciles has been reducing, however, the ratio of co-payment to income is still higher for low income deciles than for higher income deciles.

\section{DATA AND METHODS}

This study investigates the extent of equity in the delivery of health care in Taiwan from eight social dimensions, including age, sex, income, insurance status, family size, region, rurality, and catastrophic disease status. The delivery of health care examined includes total medical utilization and its two major components, outpatient care and inpatient care. To assess the extent of equity in the delivery of health care, this study calculates concentration index for medical expenditure and illness (catastrophic disease), respectively; then calculates inequity index of health care utilization.

The data analyzed in this study combines 1999 tax files provided by the Ministry 
of Treasury and 1999 to 2001 health care utilization files provided by the Bureau of National Health Insurance, using social insurance ID number as the link between both types of data files. The tax files come from a population of $11,310,000$ households, of which 4,910,000 households have filed tax forms and 6,400,000 households have not filed tax forms. This household population has been stratified by ten household income deciles. The tax file data was then sampled from each decile of the population with the sampling fraction of $1 / 50$. The health care utilization files were matched with the tax file of 1999 , and the total sample size includes 226,280 households $(584,316$ persons).

\section{RESULTS}

\section{Income}

To take into account of the effect of family economies scale for consumption, this study uses equivalent income as the variable to rank health care utilization, where equivalent income (EI) has been calculated as a function of total family income (FI) and family size $(\mathrm{FS})$ : $\mathrm{EI}=\mathrm{FI} /\left(\mathrm{FS}^{* *} 0.77\right)$. Table $1 \mathrm{~A}$ to Table $1 \mathrm{C}$ reports the distribution of individual health care utilization ranked by equivalent income decile for total medical expenditure, (western) outpatient care, and inpatient care, respectively. Table 1A indicates that total medical expenditure has increased consecutively from 1999 to 2001, and its distribution indicates progressive pattern; that is, those persons in the higher income rank have higher total medical expenditure. However, the magnitude of progressivity is moderate and its change is small over the three years, the index of concentration for total medical expenditure is between 0.024 and 0.029 . With some exception, total number of health care use is positively related 
to income. One thing worth noting is that persons in the highest income rank have the highest total medical expenditure and total number of health care use.

In this study we apply the concept of Kakwani index but replace the measure of income by medical expenditure in calculating such index, since the concentration index of total medical expenditure is smaller than the concentration index of income, the Kakwani of total medical expenditure will be negative $\left(K I=C^{\exp }-C^{i n c}\right)$. For example, for the year of $1999, K I=0.024-0.508=-0.484$, the $K I$ value of -0.484 indicates that the poor have relatively less income share but consume relatively more share of medical expenditure; that is, under NHI scheme health care use of the poor is not deterred by their low income.

The result of Table 1B for outpatient care has similar pattern with that of Table 1A, the concentration index of outpatient care is between 0.034 and 0.036 , not much fluctuation between 1999 and 2001. However, the magnitude of the index for outpatient care expenditure is higher than that of total expenditure, this indicates that the distribution of outpatient care expenditure is more uneven (progressive) than that of total medical expenditure.

Table 1C displays the distribution of inpatient care expenditure, its result has different pattern with that of outpatient care expenditure (Table 1B). The concentration index of inpatient care is negative in $1999(-0.008)$, it implies that the distribution of inpatient care expenditure is regressive; that is, the poor have higher inpatient care expenditure than the rich. In addition, Table $1 \mathrm{C}$ indicates that persons in the lowest income rank have the highest inpatient care expenditure and total number 
of inpatient days. The index value becomes positive in 2000 and 2001, but the magnitude is rather small.

Compare the result from Table 1A to $1 \mathrm{C}$, we find that although high income group has higher outpatient care expenditure (the distribution is progressive), it is the low income group that has higher inpatient care expenditure (the distribution is regressive or weak progressive), as a result, the magnitude of concentration index for total medical expenditure tend to be smaller than that of outpatient care expenditure. It is therefore important to decompose total medical expenditure into its components when examining the distribution of health care use.

\section{Family Size}

Table $2 \mathrm{~A}$ to $2 \mathrm{C}$ displays the distribution of individual health care utilization ranked by family size for total medical expenditure, outpatient care, and inpatient care, respectively. The result in Table 2A shows that two-person families have the highest total medical expenditure and total number of health care use, followed by seven-person and eight-person families, whereas four-person and five-person families have the lowest total medical expenditure. The reason that causes such distribution may be due to family composition, two-person families may be elderly couples with adult children that have filed tax income separately from their parents, and seven-person and eight-person families may be those families that include elderly and frail dependents, either situation will tend to have higher total medical expenditure. On the other hand, four-person and five-person families tend to be young couples with young children, therefore tend to have lower total expenditure. 
The result in Table 2B indicates that two-person families have the highest outpatient care expenditure and total number of outpatient care, however, it is the one-person families that have the lowest outpatient expenditure and total number of outpatient care. In Table $2 \mathrm{C}$ the result shows that two-person families also have the highest inpatient use in terms of expenditure and days of hospitalization, much higher than the other types of families. In addition, four-person and five-person families have the lowest inpatient expenditure and days of hospitalization, similar to the pattern of total medical expenditure and times of health care use.

\section{Age}

Table 3A to Table 3C shows the distribution of personal health care utilization ranked by age decile for total medical expenditure, outpatient care, and inpatient care, respectively. In Table 3A except for the youngest age group, total medical expenditure has positive correlation with age, and for the oldest two age groups, total medical expenditure accelerates rapidly. For example, the oldest age group alone uses approximately ten third share of the whole distribution of medical expenditure. If we include the oldest two age groups, they would take about one half share of the distribution of total expenditure. As for the youngest age group, its share of total medical expenditure and number of health care use is also relatively high. The result in Table 3A indicates that age has very strong correlation with total medical expenditure, especially for the youngest and the oldest (two) age groups.

Table 3B for outpatient care shows similar pattern as that of Table 3A.The result in Table $3 \mathrm{C}$ indicates the significant influence of age on hospital use, the oldest age group has the highest inpatient expenditure and inpatient days, much higher than the 
other age groups. If we include the oldest two age groups, their inpatient expenditure share would be 60 percent of the whole distribution.

\section{Insurance Status}

Table 4A to 4C displays the distribution of personal health care utilization classified by NHI insurance status for total medical expenditure, outpatient care, and inpatient care, respectively. NHI classifies the insured into six status categories based on the characteristics of employment status and occupation. Specifically, the six insurance status categories include: (I) public servants, teachers in public and private schools, employees in public and private enterprises, employers, the self-employed, and professionals; (II) laborers of occupational unions, and seamen; (III) farmers and fishermen; (IV) nonprofessional soldiers, students from military school, dependents of soldiers; (V) low-income families members that qualified for social assistance; (VI) veterans, dependents of veterans, and persons who have retired or unemployed.

Table 4A shows that category $\mathrm{V}$ (low-income persons) has the highest total medical expenditure, followed by category III (farmers and fishermen) and category VI (veterans and the unemployed), whereas category I (the employees and employers) has the lowest total expenditure. In terms of total number of health care use, category IV has the highest frequencies, followed by category III. Table 4B also shows similar pattern as of Table 4A. The result in Table 4C indicates the strong negative effect of economic resources on the use of inpatient care, for example category V (low-income persons) uses about twice to four times of hospital care in terms of inpatient expenditure and hospital stays as for the other categories, whereas category I (the employees and employers) uses the least amount of inpatient care (expenditure and 
hospital stays). This result is very consistent with the findings that the poor suffer from double jeopardy of poverty and ill health.

\section{Sex}

Table 5A to 5C displays the distribution of personal health care utilization classified by sex for total medical expenditure, outpatient care, and inpatient care, respectively. In Table 5A the result shows that women have relatively lower medical expenditure whereas higher number of health care use than men (21 times versus 19 times). The result in Table 5B indicates similar pattern; women tend to have lower outpatient expenditure but higher number of outpatient use than men.

On the other hand, Table $5 \mathrm{C}$ reports different pattern, men tend to have higher inpatient expenditure and days of hospitalization than women. The underlying reason that causes such gender differential in the use of health care may be that women tend to have higher propensity than men to seek for medical care when facing with minor health problem, however men tend to delay seeking for medical care until face with more acute health problem. So when men seek medical help, usually their health is in more acute stage of illness that requires more intensive outpatient care or hospitalization. In addition, men tend to face higher risk factors that may endanger their lives than women, therefore results in higher risk of acute care use and hospitalization than women. The above gender differential in health care use is approximately consistent with the finding that women tend to have higher rate of morbidity whereas men tend to have higher rate of mortality. 


\section{Region}

Under the scheme of NHI, Bureau of National Health Insurance (BNHI) is responsible for the affairs of insurance transaction and premium collection. There are six divisions of BNHI, which are classified by geographic region of Taiwan. Specifically, the six divisions of BNHI include: (1) Taipei Division, including the northern part of Taiwan, such as Taipei city, Taipei county, Keelung city, I-lan county, Kinmen, and Matsu island; (2) Northern Division, including the middle-northern part of Taiwan, such as Hsinchu city, Hsinchu county, Taoyuan county, and Miaoli county; (3) Middle Division, including the middle part of Taiwan, such as Taichung city, Taichung county, Changhua county, and Nan-tou county; (4) Southern Division, including the middle-southern part of Taiwan, such as Tainan city, Tainan county, Chia-yi city, Chia-yi county, and Yuon-lin county; (5) Kaoping Division, including the southern part of Taiwan, such as Kaohsiung city, Kaohsiung county, Pingtung county, and Penghu county; (6) Eastern Division, including the eastern part of Taiwan, such as Hualien county and Taitung county.

Table $6 \mathrm{~A}$ to $6 \mathrm{C}$ displays the distribution of personal health care utilization classified by the divisions of BNHI for total medical expenditure, outpatient care, and inpatient care, respectively. Table $6 \mathrm{~A}$ indicates that people in the eastern part of Taiwan (Eastern Division) have the highest total medical expenditure, and people in the middle part of Taiwan (Middle Division) have the highest times of health care use. On the other hand, people in the northern part of Taiwan (Taipei Division) have the lowest amount of health care utilization in terms of expenditure and number of health care use. 
Table 6B for outpatient care indicates different pattern from that of Table $6 \mathrm{~A}$, it is people from middle southern Taiwan (Southern Division) that have the highest medical expenditure and times of health care use, followed by people in the southern part of Taiwan (Kaoping Division), but people in the northern part of Taiwan (Taipei Division) still use the least amount of outpatient care in terms of expenditure and volume. The result in Table $6 \mathrm{C}$ clearly indicates that people in the eastern part of Taiwan (Eastern Division) have the highest inpatient expenditure and days of hospitalization, and there are virtually no differences between people from the other regions of Taiwan, this pattern also explains why people in the eastern part of Taiwan have the highest total medical expenditure than people from the other regions (see result in Table 6A).

The results from Table $6 \mathrm{~A}$ to $6 \mathrm{C}$ indicate that geography is strongly related to the use of health care, since the Eastern Division includes the most rural areas of Taiwan, the finding is not surprising that people from the eastern part of Taiwan have the highest total medical expenditure, inpatient expenditure and days of hospitalization. Such pattern probably reflects that people living in the eastern part of Taiwan suffer more from acute ill health condition and inpatient care becomes the major type of medical treatment. The Taipei Division includes the most urbanized areas in Taiwan, people from these areas tend to have higher socioeconomic status, and therefore better health condition; consequently, people from these areas use the least amount of health care in terms of outpatient and inpatient care. 


\section{Rurality}

Table 7A to 7C displays the distribution of personal health care utilization classified by remote status for total medical expenditure, outpatient care, and inpatient care, respectively. Table 7A indicates that people living in remote areas have higher total medical expenditure and frequency of health care use than those from non-remote areas, although the expenditure share of remote areas is less than $2 \%$. The result in Table 7B and Table 7C shows similar pattern as that in Table 7A. People from remote areas have relatively higher outpatient and inpatient care utilization. For example, total number of outpatient care for remote areas versus non-remote areas is 19.7 times versus 14.2 times, the statistics for hospitalization stays is 1.39 days versus 0.96 days. Since past research has found positive relation between one's socioeconomic status and health status, it may be that people from remote areas tend to be socio-economically disadvantaged; therefore they tend to have poorer health and use more health care than people from non-remote areas.

\section{Catastrophic Disease}

Table $8 \mathrm{~A}$ to $8 \mathrm{C}$ reports the distribution of personal health care utilization classified by catastrophic disease status for total medical expenditure, outpatient care, and inpatient care, respectively. As expected, people who have catastrophic disease have dramatically higher total medical expenditure than those not having such disease, and their share of expenditure constitutes about $20 \%$ of the whole distribution. Table $8 \mathrm{~B}$ for outpatient care and Table $8 \mathrm{C}$ for inpatient care also indicate similar pattern. Specifically, people with catastrophic disease in average use 30.6 times of outpatient care, and 13.2 days of inpatient care; the relevant statistic for those not having such 
disease is 13.9 times and 0.7 days. The results from Table $8 \mathrm{~A}$ to Table $8 \mathrm{C}$ shows how important the implementation of NHI to those people having catastrophic disease, it is this group of population benefits the most from NHI.

\section{Income Differential of Catastrophic Disease}

Table 9 reports the distribution of catastrophic disease incidence ranked by equivalent income decile from 1999 to 2001. As we can see from Table 9, the incidence of catastrophic disease is relatively higher toward the two extremes of the income distribution, with the fifth income decile having the lowest rate of catastrophic incidence. Table 9 also calculates the concentration index of illness using catastrophic disease as a proxy measure, the index value of 0.019 in 1999 shows that in average, taking account of the $U$ shape income pattern of disease distribution, the higher the income level, the higher the incidence of catastrophic disease; the magnitude of such progressivity is rather small, but has slightly increase from 1999 to 2001, up to 0.033 .

Table 9 also calculates inequity index of health care $(H I)$, where $H I$ equals the difference between concentration index of medical expenditure (calculated from Table 1A) and concentration index of illness (as proxy of medical need). The $H I$ value of 1999 is equal to 0.00485 , then decreases to 0.00106 in 2000 , and becomes negative value of -0.00591 in 2001 . The value of $H I$ changes from positive to negative over time means that under the NHI scheme, the distribution of health care delivery changes from being slightly favorable to the rich to slightly favorable to the poor. 


\section{Cross-National Comparison of the Equity in Health Care Delivery}

Generally speaking, cross-national comparison of the equity in health care delivery has to consider the appropriateness of the variable measures and the analytic techniques when making comparison. In order to evaluate Taiwan's general standing of equity in health care delivery, Table 10 reports the inequity index of several OECD countries for cross-national comparison. The first panel in Table 10 compares Taiwan with three OECD countries, the HI values reported in the first panel define $\mathrm{HI}=\stackrel{\text { EXP }}{\mathrm{C}}$ C . The first panel indicates that Italy has the highest value of HI (0.118), followed by the Netherlands (0.038), UK (0.014), and Taiwan $(-0.006)$. The three OECD countries all have positive value of HI (cited from Wagstaff et al, 1994), whereas Taiwan has negative value of HI, this means that health care delivery is more favorable to the rich in the three OECD countries, but (slightly) more favorable to the poor in Taiwan (for the year of 2001).

Although not directly comparable, Table 10 also reports in the second and the third panels the $H I$ values of several OECD countries based on different calculation method. Specifically, the $H I$ values in the second and third panel are standardized concentration index of medical expenditure, using health risk factors as adjustment; the interpretation of it is similar to the $H I$ reported in the first panel. The second panel of HI values are cited from Lairson et al (1995), these statistics indicate that Spain has the highest value of $H I$ (2.000), followed by Australia (0.060), US (0.018), UK (0.000), and Denmark (-0.100). The third panel of $H I$ values is cited from Wagstaff and van Doorslaer (1993), and the $H I$ ranking in descending order is Spain (0.146), U.S. (0.028), the Netherlands (0.025), U.K. (0.013), Italy (-0.036), Switzerland 
(-0.043), Denmark (-0.055), and Ireland (-0.076).

If we examine the overlapping countries in the second and the third panel, the ranking of $H I$ value in descending order are as follows: Spain, U.S., U.K., and Denmark. The highest three countries virtually have positive $H I$ values, only Denmark has negative $H I$ values. Although the result in the second and the third panel comes from different studies, the ranking of $H I$ for the four countries is rather stable, since both panel's results are based on the same measure of $K I$ (standardized concentration index of medical expenditure).

\section{CONCLUSION}

This study examines the extent of equity in the delivery of health care in Taiwan; in addition, this study investigates the stratification of health care utilization across different social groups. The content of health care examined includes total medical utilization, and the delivery of its two components, namely, outpatient care and inpatient care. The data analyzed come from 1999 to 2001 matched data of tax returns files (collected by Ministry of Treasury) and health care utilization files (collected by BNHI).

The analysis of this study finds that the distribution of total medical expenditure is progressive with income; however, the magnitude is moderate over the three years examined. Total medical expenditure varies with family size, with two-person families having the highest average expenditure and frequencies of utilization, followed by seven-person and eight-person families. Except for the youngest age 
group, age has strong positive relation with total medical expenditure, especially for the two oldest age groups. In terms of insurance status, this study finds low-income families (families on social assistance) have the highest total medical expenditure. Women tend to have lower total medical expenditure, but higher frequencies of health care utilization compared to men. Among the six regions in Taiwan, people in the eastern part of Taiwan have the highest total medical expenditure. As expected, people living in remote areas and those with catastrophic disease have much higher health care utilization in terms of expenditure and frequency than those living in non-remote areas and those not having catastrophic disease, respectively.

In addition, this study finds the extent of progressivity is slightly greater for outpatient care expenditure than for total medical expenditure. Among the six regions, it is people in the middle southern part of Taiwan having the highest average outpatient expenditure and frequency of use. The stratification of income, family size, age, insurance status, sex, rurality, and catastrophic disease is similar for the distribution of total health care and outpatient care.

In contrast to the result for outpatient care, the distribution of inpatient care in terms of expenditure and frequency is regressive, with the lowest income decile has the highest inpatient utilization (expenditure and frequency). The variation across different family size and age groups is similar for inpatient care as for total health care, but the age effect is especially strong for inpatient care, for example, the oldest age group uses about $40 \%$ of the whole distribution of medical expenditure. The low-income families have dramatically high inpatient expenditure than the rest of 
other insurance groups, this implies that such families have suffered double jeopardizes of poverty and ill health condition, since NHI provides free health care to low-income families, such families benefit substantially from the establishment of NHI. Furthermore, men have higher inpatient utilization in terms of expenditure and hospitalization stays than women, different from the pattern found for total health care and outpatient care. People living in the eastern part of Taiwan use the highest volume of inpatient care than people in the other regions; this implies that geographic region is related to its inhabitants' general health status.

The results found in this study have several implications:

First, this study finds the inequity index of Taiwan's health care delivery is negative, although the magnitude is very small, close to zero. The small negative value of $H I$ indicates that Taiwan's health care delivery is slightly favorable to the poor; however, with the small magnitude of $H I$, we should not interpret this index overly optimistic. The study of Lairson et al (1995) found that using self-evaluated health status in calculating $K I$, the result would be more favorable to the rich. Since our data do not include self-evaluated health status measure, we have to rely on catastrophic disease status in calculating KI. Future research should engage in collecting representative survey data that include self-evaluated health status in order to explore whether Taiwan has the same pattern found in Lairson et al's study.

Compared to other OECD countries, Taiwan's performance of equity in health care delivery stands at the moderate level, not being favorable to the rich, nor to the poor. However, considering the poorer health status of the socially disadvantaged, the 
allocation of Taiwan's health care delivery should be directed toward more favorable to the poor to take into account their higher need of health care.

Second, this study finds that health care utilization in terms of expenditure and frequency varies substantially with income, family size, age, rurality, and catastrophic disease status. In contrast, there are less consistent patterns of health care utilization with regard to insurance status, sex and region. Moreover, insurance status and region is not as good as income and rurality as a good proxy to predict ability to pay and health care resource, respectively. Future health care policies should take more concerns on income (ability to pay), family size, age, catastrophic disease status (medical need), and rurality (access of medical care) in the allocation of health care resource.

Third, this study finds that two-person families and seven-person/eight-person families have relatively high volume of health care utilization, this may be related to family composition or family size, which should be investigated in the future study. In addition, this study finds that low-income families have the highest health care utilization in terms of outpatient and inpatient care. Although low-income families entitle free health care under the scheme of NHI, this group deserves more social protection from the government. 


\section{REFERENCE}

Cheng, S. H., T. L. Chiang

1997 "The Effect of Universal Health Insurance on Health Care Utilization in Taiwan: Results from A Natural Experiment.” JAMA 278: 89-93.

1998 "Disparity of Medical Care Utilization among Different Health Insurance Schemes in Taiwan." Social Science Medicine 47: 613-620.

Cheng, W. H., H. J.Yeh, J. J. Su, and C. H. Cheng

1999 The Distribution of Financial Burden and Medical Utilization among the Insured Families in Taiwan's National Health Insurance, sponsored by Bureau of National Health Insurance, Department of Health.

Cheng, W. H., L. F. Chou, C. C. Chen, and C. T. Liang

2002 The Assessment of the Impact of NHI Adjustment Program on the Financial Burden for the Insured Families, sponsored by Bureau of National Health Insurance, Department of Health.

Culyer, A.J.

1980 The Political Economy of Social Policy, Oxford: Martin Robertson.

Donaldson, C., and K. Gerard

1993 Economics of Health Care Financing: The Visible Hand. New York: St. Martin's Press.

Glendinning A., L. Hendry, and J. Shucksmith

1995 "Lifestyle, Health and Social Class in Adolescence." Social Science and Medicine 41(2): 235-248.

House, J. S., et al

1994 "The Social Stratification of Aging and Health." Journal of Health and Social Behavior 35(September): 213-234.

Hsiao, W. C., and J. F. Lu

2000 “Taiwan's National Health Insurance: The Balance between Equity and Efficiency." Working paper, an earlier version was presented at the Professor Kuo-Shu Liang's 4th Memorial Conference, 1999, Taipei, Taiwan. 
Hurst, J.

1985 Financing Health Care in the U.S.A., Canada and Britain. London: Kings Fund Institute.

Kunst, A. E., and J. P. Mackenbach

1994 "International Variation in the Size of Mortality Differences Associated With Occupational Status.” International Journal of Epidemiology 23: 742-750.

Lairson, D.R., P. Hindson, and A. Hauquitz

1995 "Equity of Health Care in Australia.” Social Science Medicine 41: 475-482.

Le Grand, J.

1978 "The Distribution of Public Expenditure: The Case of Health Care." Economica 45: 125-142.

Le Grand, J., and R. Robison

1984 The Economics of Social Problems, London: Macmillan.

Lo, J. C.

1998 “The Impacts of National Health Insurance on Income Distribution.” Industry of Free China 11(88): 1-41.

Maynard, A., and A.Williams

1984 "Privatisation and the National Health Service." in J. Le Grand and R. Robinson (eds.), Privatisation and the Welfare State, London: Allen and Unwin.

O`Connell, O., and C. Propper

1990 "Equity and the Distribution of National Health Service Resources." Journal of Health Economics, 10(1): 1-20.

Rahkonen, O., S. Arber, and E. Lahelma

1995 "Health Inequalities in Early Adulthood: A Comparison of Young Men and Women in Britain and Finland.” Social Science and Medicine 41(2): 163-171.

Ross, C. E., and C. L. Wu

1995 “The Links Between Education and Health." American Sociological Review 60(October): 719-745. 
Siegrist, J.

1987 Social Inequalities in Health: Evaluating the European Region. Copenhagen: World Health Organization Regional Office for Europe.

Sundquist, J., and S. E. Johansson

1997 "Indicators of Socio-economic Position and Their Relation to Mortality in Sweden." Social Science and Medicine 45(12): 1757-1766.

Terris, $\mathrm{M}$.

1992 "Budget Cutting and Privatization: The Threat to Health." Journal of Public Health Policy 13(1)

Tsay, J. H.

1999 "Horizontal Equity in the Premium Burdens for National Health Insurance in Taiwan." Paper presented at the International Conference on Family, Social Policies and Financial Strategies, held by Taiwanese Social Welfare Association, Taipei, Taiwan.

Tsay, J. H., and Y. J. Chou

2002 "Economies of Scale, Household Size, and Inequality in Health Care Finance in Taiwan, 1995-2000." Paper presented at the International Conference on Allocation of Social and Family Resources in Changing Societies, held by Sun Yat-Sen Institute for Social Science and Philosopy, Academia Sinica, Taipei, Taiwan.

Wagstaff, A., and E. van Doorslaer

1993 "Equity in the Delivery of Health Care: Methods and Findings." Pp.49-87 in Equity in the Finance and Delivery of Health Care : An International Perspective, edited by E. van Doorslaer, A. Wagstaff, and F. Rutten. Oxford: Oxford University Press.

Wagstaff, A., E. van Doorslaer, and P. Paci

1994 "Equity in the Finance of Health Care: Some Tentative Cross-Country Comparisons." Pp.141-171 in Providing Health Care: The Economics of Alternative Systems of Finance and Delivery, edited by A. McGuire, P. Fenn, and K. Mayhew. New Youk: Oxford University Press. 
Wilkinson, R. G.

1986 "Income and Mortality." Pp. 88-114 in Class and Health: Research and Longitudinal Data, edited by Richard G. Wilkinson. London and New York: Tavistock Publications.

Valkonen, $\mathrm{T}$.

1989 "Adult Mortality and Level of Education: A Comparison of Six Countries." Pp.142-162 in Health Inequalities in European Countries, edited by J. Fox. Aldershot, U.K. : Grower.

van Doorslaer, E. et al

2000 "Equity in the Delivery of Health Care in Europe and the U.S." Journal of Health Economics 19: 553-583.

Yeh, H. J., Y. C. Chan, and C. Wang

1998a "Equity and Efficiency in Premium Subsidies of Taiwan's National Health Insurance." Socioeconomic Law and Institution Review No. 21 (January): 347-381.

1998b "Subsidies for Middle-to-Low Income Households in Taiwan's National Health Insurance." Proceedings of the National Science Council Vol 8 (2): 260-275.

Yeh, H. J.

1999 "Equity in Health Care for National Health Insurance-An Empirical Analysis of Taiwan." Paper presented at the International Conference on Family, Social Policies and Financial Strategies, held by Taiwanese Social Welfare Association, Taipei, Taiwan. 


\section{Table 1A Distribution of Personal Total Health Care Utilization}

\section{Ranked by Equivalent Income Decile}

Unit: NT\$, \%

\begin{tabular}{|c|c|c|c|c|c|c|c|c|c|c|c|c|}
\hline \multirow{2}{*}{$\begin{array}{l}\text { Equivalent } \\
\text { Income } \\
\text { Decile }\end{array}$} & & & & & \multirow{2}{*}{\multicolumn{4}{|c|}{2000}} & \multirow{2}{*}{\multicolumn{4}{|c|}{2001}} \\
\hline & \multicolumn{4}{|c|}{1999} & & & & & & & & \\
\hline 2 & 14384.12 & 10.17 & 1090.16 & 14.0478 & 14948.72 & 10.30 & 1332.64 & 13.5464 & 15381.69 & 10.21 & 1380.75 & 13.2029 \\
\hline 3 & 13626.5 & 9.63 & 1076.99 & 13.6745 & 14142.2 & 9.74 & 1310.38 & 13.4272 & 14711.50 & 9.76 & 1333.65 & 13.0625 \\
\hline 4 & 13031.64 & 9.21 & 1073.64 & 13.4428 & 13259.24 & 9.13 & 1275.1 & 13.2021 & 13989.14 & 9.28 & 1318.56 & 12.7252 \\
\hline 6 & 12603.64 & 8.91 & 1093.00 & 13.9824 & 13017.23 & 8.97 & 1329.42 & 13.5262 & 13577.65 & 9.01 & 1354.16 & 12.9846 \\
\hline 7 & 14176.27 & 10.02 & 1230.71 & 14.5456 & 14510.48 & 9.99 & 1452.52 & 14.7584 & 15184.05 & 10.07 & 1482.03 & 14.1994 \\
\hline 8 & 14511.64 & 10.26 & 1214.95 & 15.4018 & 15357.2 & 10.58 & 1491.25 & 14.7868 & 15955.63 & 10.59 & 1534.63 & 14.4187 \\
\hline 9 & 15562.59 & 11.00 & 1255.77 & 16.0816 & 15737.67 & 10.84 & 1537.95 & 14.9514 & 16103.72 & 10.68 & 1579.98 & 14.5642 \\
\hline 10 & 16566.6 & 11.71 & 1343.05 & 16.1359 & 17233.77 & 11.87 & 1648.23 & 14.7108 & 17712.77 & 11.75 & 1680.06 & 14.4932 \\
\hline
\end{tabular}




\section{Table 1B Distribution of Personal Outpatient Care Utilization}

\section{Ranked by Equivalent Income Decile}

Unit: NT\$, \%

\begin{tabular}{|c|c|c|c|c|c|c|c|c|c|c|c|c|}
\hline \multirow{2}{*}{$\begin{array}{l}\text { Equivalent } \\
\text { Income } \\
\text { Decile }\end{array}$} & \multicolumn{4}{|c|}{1999} & \multicolumn{4}{|c|}{2000} & \multicolumn{4}{|c|}{2001} \\
\hline & Expenditure & Percentage & Copayment & Times & Expenditure & Percentage & Copayment & Times & Expenditure & Percentage & Copayment & Times \\
\hline 1 & 8020.73 & 9.90 & 810.497 & 11.4147 & 7872.63 & 9.63 & 800.94 & 10.8850 & 8141.21 & 9.76 & 816.21 & 10.4885 \\
\hline 2 & 8150.38 & 10.06 & 723.717 & 11.911 & 8231.62 & 10.07 & 838.01 & 11.3946 & 8320.19 & 9.97 & 852.49 & 11.0470 \\
\hline 3 & 7686.03 & 9.49 & 719.862 & 11.7557 & 7886.61 & 9.64 & 829.23 & 11.2730 & 8107.97 & 9.72 & 837.39 & 10.8473 \\
\hline 4 & 7469.90 & 9.22 & 708.318 & 11.5915 & 7517.99 & 9.19 & 811.38 & 11.0746 & 7676.79 & 9.20 & 813.84 & 10.5468 \\
\hline 5 & 7053.46 & 8.71 & 723.577 & 11.7518 & 7103.33 & 8.68 & 820.38 & 11.2571 & 7238.09 & 8.67 & 813.83 & 10.6620 \\
\hline 6 & 7130.98 & 8.80 & 730.376 & \begin{tabular}{|l|}
11.7299 \\
\end{tabular} & 7215.02 & 8.82 & 839.78 & 11.2742 & 7268.84 & 8.71 & 835.86 & 10.6971 \\
\hline 7 & 8135.89 & 10.04 & 850.654 & 12.8461 & 8297.50 & 10.14 & 936.63 & 12.3182 & 8390.53 & 10.05 & 935.01 & 11.7562 \\
\hline 8 & 8715.54 & 10.76 & 831.949 & 12.9032 & 8826.20 & 10.79 & 962.41 & 12.3769 & 9114.19 & 10.92 & 979.90 & 11.9582 \\
\hline 9 & 9079.41 & 11.21 & 861.151 & 12.9393 & 9110.10 & 11.14 & 1007.73 & 12.4058 & 9218.98 & 11.05 & 1014.44 & 11.9810 \\
\hline 10 & 9563.59 & 11.81 & 890.833 & 12.6178 & 9731.39 & 11.90 & 1064.69 & 12.1483 & 9970.97 & 11.95 & 1096.88 & 11.8861 \\
\hline Average & 8100.59 & 100.00 & 785.093 & 12.1461 & 8179.24 & 100.00 & 891.12 & 11.6408 & 8344.78 & 100.00 & 899.59 & 11.1870 \\
\hline $\begin{array}{c}\text { Concentration } \\
\text { Index }\end{array}$ & & 0.03414 & & & & 0.03666 & & & & 0.03586 & & \\
\hline
\end{tabular}




\section{Table 1C Distribution of Personal Inpatient Care Utilization}

\section{Ranked by Equivalent Income Decile}

\begin{tabular}{|c|c|c|c|c|c|c|c|c|c|c|c|c|}
\hline \multicolumn{13}{|c|}{ Unit: NT\$, \% } \\
\hline \multirow{2}{*}{$\begin{array}{c}\text { Equivalent } \\
\text { Income } \\
\text { Decile }\end{array}$} & \multicolumn{4}{|c|}{1999} & \multicolumn{4}{|c|}{2000} & \multicolumn{4}{|c|}{2001} \\
\hline & Expenditure & Percentage & Copayment & Days & Expenditure & Percentage & Copayment & Days & Expenditure & Percentage & Copayment & Days \\
\hline 1 & 5089.07 & 11.84 & 268.711 & 1.03834 & 4773.05 & 10.63 & 249.170 & 0.94482 & 5053.21 & 10.60 & 273.094 & 0.98335 \\
\hline 2 & 4607.14 & 10.72 & 232.897 & 0.92143 & 4979.42 & 11.09 & 243.234 & 0.93582 & 5248.74 & 11.00 & 257.396 & 0.97779 \\
\hline 3 & 4291.32 & 9.99 & 220.250 & 0.85537 & 4528.54 & 10.09 & 225.478 & 0.88277 & 4743.54 & 9.95 & 221.669 & 0.88953 \\
\hline 4 & 3966.15 & 9.23 & 234.425 & 0.80383 & 4034.27 & 8.98 & 221.598 & 0.79567 & 4498.89 & 9.43 & 243.665 & 0.85815 \\
\hline 5 & 3748.64 & 8.72 & 213.289 & 0.75335 & 3891.72 & 8.67 & 201.414 & 0.77136 & 4113.91 & 8.63 & 206.415 & 0.77042 \\
\hline 6 & 3761.92 & 8.76 & 220.933 & 0.76935 & 3998.09 & 8.91 & 224.297 & 0.78813 & 4389.84 & 9.20 & 236.006 & 0.81499 \\
\hline 7 & 4178.71 & 9.72 & 226.660 & 0.82080 & 4250.48 & 9.47 & 230.884 & 0.82970 & 4754.47 & 9.97 & 245.940 & 0.87247 \\
\hline 8 & 3912.18 & 9.11 & 228.589 & 0.79462 & 4563.93 & 10.16 & 250.545 & 0.83145 & 4761.87 & 9.98 & 250.401 & 0.86143 \\
\hline 9 & 4501.15 & 10.48 & 234.860 & 0.88600 & 4538.75 & 10.11 & 234.622 & 0.86711 & 4689.43 & 9.83 & 253.786 & 0.85419 \\
\hline 10 & 4913.15 & 11.43 & 289.781 & 0.87796 & 5336.48 & 11.89 & 288.041 & 0.93387 & 5442.96 & 11.41 & 272.084 & 0.92165 \\
\hline Average & 4296.94 & 100.00 & 237.040 & 0.85211 & 4489.47 & 100.00 & 236.928 & 0.85807 & 4769.69 & 100.00 & 246.046 & 0.88040 \\
\hline $\begin{array}{c}\text { Concentration } \\
\text { Index }\end{array}$ & & -0.00826 & & & & 0.00654 & & & & 0.00144 & & \\
\hline
\end{tabular}




\section{Table 2A Distribution of Personal Total Health Care Utilization}

\section{Classified by Family Size}

\begin{tabular}{|c|c|c|c|c|c|c|c|c|c|c|c|c|}
\hline \multicolumn{8}{|c|}{ Unit: NT\$, \% } & & & & & \\
\hline \multirow{2}{*}{$\begin{array}{c}\text { Family } \\
\text { Size }\end{array}$} & \multicolumn{4}{|c|}{1999} & \multicolumn{4}{|c|}{2000} & \multicolumn{4}{|c|}{2001} \\
\hline & Expenditure & Percentage & Copayment & Times & Expenditure & Percentage & Copayment & Times & Expenditure & Percentage & Copayment & Times \\
\hline 1 & 12440.39 & 12.98 & 884.56 & 10.6929 & 12232.28 & 12.44 & 1073.21 & 10.5123 & 13298.89 & 13.03 & 1151.68 & 10.7375 \\
\hline 2 & 20903.98 & 22.88 & 1582.89 & 17.2028 & 22248.25 & 23.74 & 1887.85 & 16.4439 & 23365.01 & 24.01 & 1972.51 & 16.3858 \\
\hline 3 & 14961.07 & 15.43 & 1207.71 & 14.8257 & 15474.48 & 15.55 & 1486.03 & 14.4923 & 16087.67 & 15.57 & 1529.88 & 14.2201 \\
\hline 4 & 11533.95 & 17.30 & 1071.30 & 14.3366 & 11733.66 & 17.15 & 1248.18 & 13.8047 & 11779.41 & 16.59 & 1248.79 & 13.0737 \\
\hline 5 & 11842.07 & 15.31 & 1058.43 & 14.0869 & 11965.17 & 15.07 & 1255.39 & 13.4511 & 12307.88 & 14.94 & 1267.79 & 12.7403 \\
\hline 6 & 14166.99 & 9.30 & 1197.82 & 15.2187 & 14475.84 & 9.26 & 1449.39 & 14.5342 & 15081.17 & 9.29 & 1468.53 & 13.8917 \\
\hline 7 & 15164.96 & 4.18 & 1268.76 & 15.7869 & 15720.64 & 4.22 & 1528.36 & 14.9942 & 15645.10 & 4.05 & 1528.83 & 14.2002 \\
\hline 8 & 15116.19 & 2.63 & 1287.35 & 16.4443 & 15160.52 & 2.57 & 1540.47 & 15.5043 & 15497.77 & 2.53 & 1557.08 & 14.6650 \\
\hline Average & 14149.62 & 100 & 1165.28 & 14.4585 & 14518.35 & 100 & 1394.24 & 13.9189 & 15072.23 & 100 & 1429.94 & 13.5071 \\
\hline
\end{tabular}




\section{Table 2B Distribution of Personal Outpatient Care Utilization}

\section{Classified by Family Size}

\begin{tabular}{|c|c|c|c|c|c|c|c|c|c|c|c|c|}
\hline \multirow{3}{*}{$\begin{array}{c}\text { Family } \\
\text { Size }\end{array}$} & \multirow{2}{*}{\multicolumn{4}{|c|}{1999}} & \multirow{2}{*}{\multicolumn{4}{|c|}{2000}} & \multicolumn{4}{|c|}{ Unit: NT\$, \% } \\
\hline & & & & & & & & & & 200 & & \\
\hline & Expenditure & Percentage & Copayment & Times & Expenditure & Percentage & Copayment & Times & Expenditure & Percentage & Copayment & Times \\
\hline 1 & 6403.27 & 11.67 & 544.84 & 8.5762 & 6439.67 & 11.62 & 649.8 & 8.4452 & 6779.21 & 11.99 & 691.53 & 8.6154 \\
\hline 2 & 12424.98 & 23.76 & 1044.13 & 14.7172 & 12653.46 & 23.96 & 1183.79 & 14.0887 & 13159.41 & 24.43 & 1227.57 & 14.0253 \\
\hline 3 & 8527.12 & 15.36 & 807.46 & 12.5836 & 8708.26 & 15.53 & 951.36 & 12.2430 & 8989.51 & 15.72 & 973.03 & 11.8971 \\
\hline 4 & 6690.12 & 17.53 & 760.66 & 12.0050 & 6755.15 & 17.53 & 826.57 & 11.4673 & 6757.38 & 17.19 & 813.77 & 10.6942 \\
\hline 5 & 6871.83 & 15.52 & 729.68 & 11.7724 & 6871.07 & 15.37 & 814.03 & 11.1639 & 6822.06 & 14.95 & 801.49 & 10.4047 \\
\hline 6 & 8243.97 & 9.45 & 811.84 & 12.8698 & 8226.80 & 9.34 & 931.59 & 12.1964 & 8276.23 & 9.21 & 918.79 & 11.5401 \\
\hline 7 & 8525.10 & 4.10 & 849.84 & 13.4211 & 8575.76 & 4.09 & 964.39 & 12.6629 & 8589.58 & 4.01 & 941.45 & 11.8388 \\
\hline 8 & 8620.07 & 2.62 & 882.66 & 14.0320 & 8514.92 & 2.56 & 1000.46 & 13.1606 & 8489.11 & 2.55 & 978.41 & 12.2410 \\
\hline Average & 8100.59 & 100 & 785.09 & 12.1461 & 8179.24 & 100 & 891.12 & 11.6408 & 8344.77 & 100 & 899.59 & 11.1870 \\
\hline
\end{tabular}


Table 2C Distribution of Personal Inpatient Care Utilization

Classified by Family Size

\begin{tabular}{|c|c|c|c|c|c|c|c|c|c|c|c|c|}
\hline \multirow{3}{*}{$\begin{array}{c}\text { Family } \\
\text { Size }\end{array}$} & \multirow{2}{*}{\multicolumn{4}{|c|}{1999}} & \multirow{2}{*}{\multicolumn{4}{|c|}{2000}} & \multicolumn{4}{|c|}{ Unit: NTS, \% } \\
\hline & & & & & & & & & & & 001 & \\
\hline & Days & Expenditure & Percentage & Copayment & Days & Expenditure & Percentage & Copayment & Days & Expenditure & Percentage & Copayment \\
\hline 1 & 0.87890 & 4374.18 & 15.03 & 211.816 & 0.85887 & 4071.28 & 13.39 & 194.864 & 0.93886 & 4707.39 & 14.57 & 216.626 \\
\hline 2 & 1.30890 & 6612.92 & 23.84 & 379.592 & 1.42293 & 7683.74 & 26.51 & 380.637 & 1.46826 & 8215.14 & 26.68 & 400.680 \\
\hline 3 & 0.92349 & 4723.26 & 16.04 & 259.890 & 0.96316 & 4943.63 & 16.07 & 262.486 & 0.95225 & 5149.43 & 15.75 & 261.023 \\
\hline 4 & 0.61896 & 3086.89 & 15.25 & 167.972 & 0.58860 & 3098.56 & 14.65 & 165.522 & 0.56529 & 3022.47 & 13.45 & 164.716 \\
\hline 5 & 0.63432 & 3230.68 & 13.75 & 186.024 & 0.59731 & 3244.35 & 13.22 & 190.373 & 0.64108 & 3514.89 & 13.48 & 198.949 \\
\hline 6 & 0.82878 & 4159.98 & 8.99 & 241.429 & 0.83348 & 4359.21 & 9.02 & 251.297 & 0.86981 & 4820.13 & 9.39 & 260.501 \\
\hline 7 & 0.95630 & 4877.04 & 4.42 & 274.711 & 0.93167 & 5242.54 & 4.55 & 284.589 & 0.89039 & 5051.20 & 4.13 & 289.597 \\
\hline 8 & 0.94541 & 4687.95 & 2.68 & 254.255 & 0.91317 & 4749.45 & 2.60 & 265.394 & 0.92397 & 4964.03 & 2.56 & 288.399 \\
\hline Average & 0.85211 & 4296.94 & 100 & 237.040 & 0.85807 & 4489.47 & 100 & 236.929 & 0.88040 & 4769.69 & 100 & 246.046 \\
\hline
\end{tabular}




\section{Table 3A Distribution of Personal Total Health Care Utilization}

\section{Ranked by Age Decile}

Unit: NT\$, \%

\begin{tabular}{|c|c|c|c|c|c|c|c|c|c|c|c|c|}
\hline \multirow{2}{*}{$\begin{array}{c}\text { Age } \\
\text { Decile }\end{array}$} & \multicolumn{4}{|c|}{1999} & \multicolumn{4}{|c|}{2000} & \multicolumn{4}{|c|}{2001} \\
\hline & Expenditure & Percentage & Copayment & Times & Expenditure & Percentage & Copayment & Times & Expenditure & Percentage & Copayment & Times \\
\hline 1 & 11121.93 & 8.43 & 1371.54 & 20.6217 & 10141.65 & 7.48 & 1441.87 & 20.5291 & 9147.34 & 6.50 & 1286.66 & 17.7886 \\
\hline 2 & 5581.07 & 3.84 & 647.05 & 10.6810 & 5485.86 & 3.67 & 712.54 & 9.8345 & 5320.60 & 3.43 & 658.30 & 8.6872 \\
\hline 3 & 5775.53 & 4.23 & 576.91 & 8.3959 & 6162.00 & 4.40 & 692.89 & 8.3755 & 6704.83 & 4.61 & 745.19 & 8.4046 \\
\hline 4 & 7179.49 & 4.38 & 649.75 & 9.0546 & 7290.51 & 4.33 & 769.34 & 9.0822 & 8118.22 & 4.64 & 863.31 & 9.4759 \\
\hline 5 & 8794.76 & 6.47 & 746.41 & 10.5300 & 8920.80 & 6.39 & 900.99 & 10.4444 & 8946.18 & 6.17 & 941.91 & 10.3555 \\
\hline 8 & 4814.74 & 10.93 & 40.26 & 14.4069 & 524.91 & 11.16 & 1535.73 & 13.8949 & 16731.04 & 11.58 & 1655.47 & 13.9942 \\
\hline 9 & 4873.74 & 17.58 & 1993.37 & 19.7262 & 26193.35 & 18.03 & 2392.57 & 18.7097 & 22709.37 & 15.05 & 2543.20 & 18.9497 \\
\hline 10 & 42702.32 & 29.87 & 2572.76 & 26.2886 & 44187.02 & 30.10 & 3191.84 & 24.3590 & 45773.82 & 30.03 & 3200.58 & 23.9183 \\
\hline Average & 14141.63 & 100.00 & 1164.56 & 14.4433 & 14517.73 & 100.00 & 1391.27 & 13.9159 & 15073.98 & 100.00 & 1425.34 & 13.4969 \\
\hline
\end{tabular}




\section{Table 3B Distribution of Personal Outpatient Care Utilization}

\section{Ranked by Age Decile}

Unit: NT\$, \%

\begin{tabular}{|c|c|c|c|c|c|c|c|c|c|c|c|c|}
\hline \multirow{2}{*}{$\begin{array}{c}\text { Age } \\
\text { Decile }\end{array}$} & \multicolumn{4}{|c|}{1999} & \multicolumn{4}{|c|}{2000} & \multicolumn{4}{|c|}{2001} \\
\hline & Expenditure & Percentage & Copayment & Times & Expenditure $\mathrm{I}$ & Percentage & Copayment & Times & Expenditure & Percentage & Copayment & Times \\
\hline 1 & 7004.53 & 9.28 & 1104.02 & 19.1533 & 6890.87 & 9.03 & 1125.02 & 18.5875 & 5974.88 & 7.68 & 965.53 & 15.4914 \\
\hline 2 & 3320.73 & 3.99 & 481.34 & 8.5020 & 3193.09 & 3.80 & 483.64 & 7.8607 & 2965.36 & 3.46 & 431.86 & 6.8327 \\
\hline 4 & 3532.54 & 3.76 & 434.37 & 6.8484 & 3540.45 & 3.73 & 484.32 & 6.8664 & 3811.17 & 3.94 & 531.12 & 7.1129 \\
\hline 5 & 4360.58 & 5.61 & 506.78 & 8.3020 & 4361.23 & 5.55 & 572.38 & 8.1782 & 4493.36 & 5.61 & 590.74 & 8.0117 \\
\hline 8 & 9004.17 & 11.62 & 847.44 & 11.7958 & 9353.62 & 11.94 & 986.41 & 11.3762 & 9932.51 & 12.43 & 1062.98 & 11.4853 \\
\hline 9 & 15403.60 & 19.03 & 1357.69 & 17.0147 & 15981.01 & 19.53 & 1540.98 & 16.1826 & 16902.89 & 20.26 & 1652.76 & 16.4162 \\
\hline 10 & 23521.66 & 28.76 & 1485.90 & 23.7965 & 23483.55 & 28.41 & 1843.80 & 22.1084 & 23580.72 & 27.98 & 1819.74 & 21.7831 \\
\hline Average & 8087.59 & 100.00 & 784.67 & 12.1514 & 8176.12 & 100.00 & 889.01 & 11.6531 & 8335.43 & 100.00 & 896.81 & 11.1892 \\
\hline
\end{tabular}


Table 3C Distribution of Personal Inpatient Care Utilization

\section{Ranked by Age Decile}

Unit: NT\$, \%

\begin{tabular}{|c|c|c|c|c|c|c|c|c|c|c|c|c|}
\hline \multirow{2}{*}{$\begin{array}{c}\text { Age } \\
\text { Decile }\end{array}$} & \multicolumn{4}{|c|}{1999} & \multicolumn{4}{|c|}{2000} & \multicolumn{4}{|c|}{2001} \\
\hline & Expenditure & Percentage & Copayment & Days & Expenditure & Percentage & Copayment & Days & Expenditure & Percentage & Copayment & Days \\
\hline 1 & 3040.03 & 7.54 & 178.651 & 0.66245 & 1694.47 & 4.03 & 117.917 & 0.42532 & 1233.61 & 2.76 & 82.282 & 0.31909 \\
\hline 2 & 638.18 & 1.44 & 37.313 & 0.11870 & 697.14 & 1.50 & 43.273 & 0.12360 & 755.15 & 1.53 & 40.672 & 0.12379 \\
\hline 3 & 1098.13 & 2.63 & 74.274 & 0.21279 & 1271.11 & 2.92 & 75.746 & 0.24330 & 1608.37 & 3.48 & 98.372 & 0.34254 \\
\hline 4 & 1795.05 & 3.58 & 86.588 & 0.35716 & 1803.84 & 3.45 & 80.373 & 0.38105 & 2181.63 & 3.93 & 107.062 & 0.44014 \\
\hline 5 & 2706.67 & 6.52 & 106.815 & 0.57912 & 2734.41 & 6.31 & 109.978 & 0.58892 & 2515.98 & 5.46 & 114.957 & 0.55702 \\
\hline 6 & 2554.74 & 6.11 & 128.712 & 0.54507 & 2672.08 & 6.13 & 139.722 & 0.52249 & 2589.27 & 5.59 & 135.715 & 0.51134 \\
\hline 7 & 2634.08 & 5.82 & 163.983 & 0.56234 & 3014.50 & 6.38 & 187.310 & 0.59433 & 3410.80 & 6.79 & 210.110 & 0.65884 \\
\hline 8 & 3899.85 & 9.42 & 226.604 & 0.75760 & 4198.58 & 9.72 & 233.816 & 0.77541 & 4740.86 & 10.33 & 254.968 & 0.82185 \\
\hline 9 & 7452.58 & 17.25 & 451.436 & 1.39305 & 8127.19 & 18.03 & 462.973 & 1.44669 & 8675.66 & 18.10 & 470.138 & 1.49244 \\
\hline 10 & 17327.75 & 39.69 & 922.273 & 3.36443 & 18862.20 & 41.41 & 926.982 & 3.53369 & 20363.48 & 42.04 & 945.449 & 3.60877 \\
\hline Average & 4318.24 & 100.00 & 237.939 & 0.85651 & 4504.63 & 100.00 & 237.691 & 0.86250 & 4790.27 & 100.00 & 245.291 & 0.88503 \\
\hline
\end{tabular}




\section{Table 4A Distribution of Personal Total Health Care Utilization}

\section{Classified by Insurance Status}

\begin{tabular}{|c|c|c|c|c|c|c|c|c|c|c|c|c|}
\hline \multirow{3}{*}{$\begin{array}{c}\text { Insurance } \\
\text { Status }\end{array}$} & \multirow{2}{*}{\multicolumn{4}{|c|}{1999}} & \multirow{2}{*}{\multicolumn{4}{|c|}{2000}} & \multicolumn{4}{|c|}{ Unit: NT\$, \% } \\
\hline & & & & & & & & & & 2001 & & \\
\hline & Expenditure & Percentage & Copayment & Times & Expenditure & Percentage & Copayment & Times & Expenditure & Percentage & Copayment & Times \\
\hline I & 12390.89 & 39.95 & 1123.76 & 14.1087 & 12691.09 & 39.90 & 1355.69 & 13.7129 & 13049.94 & 39.64 & 1374.65 & 13.2047 \\
\hline II & 14274.37 & 19.47 & 1235.27 & 15.4327 & 14605.75 & 19.42 & 1519.93 & 14.6110 & 14969.31 & 19.23 & 1555.80 & 14.1125 \\
\hline III & 19008.81 & 21.87 & 1691.74 & 18.1301 & 19575.63 & 21.96 & 1930.72 & 17.0939 & 20510.83 & 22.23 & 1985.72 & 16.4534 \\
\hline IV & 15365.83 & 0.39 & 1531.57 & 18.6164 & 15414.12 & 0.38 & 1682.20 & 18.1235 & 16382.20 & 0.39 & 1695.24 & 17.0498 \\
\hline $\mathrm{V}$ & 28736.53 & 0.92 & 574.15 & 16.6355 & 26661.13 & 0.83 & 371.05 & 16.2277 & 23829.97 & 0.72 & 499.75 & 15.6335 \\
\hline VI & 18224.90 & 17.41 & 979.51 & 14.6146 & 18802.66 & 17.51 & 1176.72 & 14.2385 & 19768.44 & 17.79 & 1212.06 & 14.1303 \\
\hline Average & 14813.12 & 100 & 1221.59 & 15.1619 & 15192.14 & 100 & 1458.10 & 14.5733 & 15723.22 & 100 & 1489.43 & 14.0986 \\
\hline
\end{tabular}




\section{Table 4B Distribution of Personal Outpatient Care Utilization}

\section{Classified by Insurance Status}

\begin{tabular}{|c|c|c|c|c|c|c|c|c|c|c|c|c|}
\hline \multirow{3}{*}{$\begin{array}{c}\text { Insurance } \\
\text { Status }\end{array}$} & \multirow{2}{*}{\multicolumn{4}{|c|}{1999}} & \multirow{2}{*}{\multicolumn{4}{|c|}{2000}} & \multicolumn{4}{|c|}{ Unit: NT\$, \% } \\
\hline & & & & & & & & & & 2001 & & \\
\hline & Expenditure & Percentage & Copayment & Times & Expenditure & Percentage & Copayment & Times & Expenditure & Percentage & Copayment & Times \\
\hline I & 7127.90 & 40.13 & 768.94 & 11.5869 & 7222.57 & 40.34 & 885.90 & 11.1977 & 7336.94 & 40.27 & 888.82 & 10.6528 \\
\hline II & 8573.68 & 20.42 & 847.61 & 12.8337 & 8548.71 & 20.20 & 976.51 & 12.1290 & 8711.54 & 20.22 & 983.52 & 11.6106 \\
\hline III & 10903.35 & 21.91 & 1118.81 & 15.9412 & 10950.37 & 21.82 & 1201.96 & 14.9792 & 11126.87 & 21.79 & 1203.26 & 14.3466 \\
\hline IV & 8736.71 & 0.38 & 1065.74 & 16.2884 & 9028.16 & 0.39 & 1188.20 & 15.6120 & 8677.75 & 0.37 & 1140.17 & 14.2509 \\
\hline $\mathrm{V}$ & 11611.19 & 0.65 & 283.35 & 14.0566 & 11214.12 & 0.62 & 186.90 & 13.5788 & 11391.56 & 0.62 & 254.39 & 12.9776 \\
\hline VI & 9896.24 & 16.51 & 626.06 & 12.5545 & 10051.77 & 16.63 & 719.70 & 12.2045 & 10284.62 & 16.72 & 733.01 & 12.0013 \\
\hline Average & 8482.30 & 100 & 823.05 & 12.7470 & 8551.69 & 100 & 932.37 & 12.2005 & 8701.77 & 100 & 937.43 & 11.6910 \\
\hline
\end{tabular}




\section{Table 4C Distribution of Personal Inpatient Care Utilization}

\section{Classified by Insurance Status}

\begin{tabular}{|c|c|c|c|c|c|c|c|c|c|c|c|c|}
\hline & & & & & & & & & \multicolumn{4}{|c|}{ Unit: NT\$, \% } \\
\hline \multirow{2}{*}{$\begin{array}{c}\text { Insurance } \\
\text { Status }\end{array}$} & \multicolumn{4}{|c|}{1999} & \multicolumn{4}{|c|}{2000} & \multicolumn{4}{|c|}{2001} \\
\hline & Days & Expenditure & Percentage & Copayment & Days & Expenditure & Percentage & Copayment & Days & Expenditure & Percentage & Copayment \\
\hline I & 0.64762 & 3333.88 & 35.36 & 199.569 & 0.64289 & 3422.89 & 34.66 & 197.958 & 0.64574 & 3556.60 & 34.02 & 198.431 \\
\hline II & 0.76027 & 3772.01 & 16.92 & 222.484 & 0.75469 & 4067.16 & 17.42 & 241.153 & 0.77714 & 4168.57 & 16.87 & 253.220 \\
\hline III & 1.29097 & 6516.68 & 24.66 & 424.918 & 1.32240 & 6957.38 & 25.14 & 418.439 & 1.37232 & 7649.32 & 26.11 & 453.311 \\
\hline IV & 1.07613 & 4928.03 & 0.41 & 330.281 & 0.91801 & 4472.74 & 0.35 & 248.102 & 1.12250 & 5484.41 & 0.41 & 275.607 \\
\hline $\mathrm{V}$ & 3.04355 & 15270.9 & 1.60 & 222.231 & 3.01272 & 13453.6 & 1.35 & 44.276 & 2.56570 & 10427.10 & 0.99 & 85.532 \\
\hline $\mathrm{VI}$ & 1.37284 & 6694.79 & 21.04 & 241.172 & 1.41406 & 7023.38 & 21.07 & 228.808 & 1.46187 & 7622.54 & 21.60 & 223.884 \\
\hline Average & 0.89557 & 4502.77 & 100 & 249.083 & 0.90263 & 4716.21 & 100 & 248.083 & 0.92245 & 4992.71 & 100 & 256.291 \\
\hline
\end{tabular}




\section{Table 5A Distribution of Personal Total Health Care Utilization}

\section{Classified by Sex}

\begin{tabular}{|c|c|c|c|c|c|c|c|c|c|c|c|c|}
\hline \multirow{3}{*}{ Sex } & & & & & & & & & & & Unit: NT\$ & $\%$ \\
\hline & \multicolumn{4}{|c|}{1999} & \multicolumn{4}{|c|}{2000} & \multicolumn{4}{|c|}{2001} \\
\hline & Expenditure & Percentage & Copayment & Times & Expenditure & Percentage & Copayment & Times & Expenditure & Percentage & Copayment & Times \\
\hline Women & 18689.46 & 51.74 & 1690.26 & 20.9685 & 18931.14 & 51.50 & 2011.55 & 19.9802 & 19686.59 & 50.79 & 2076.98 & 19.6183 \\
\hline Men & 20113.68 & 48.26 & 1488.95 & 18.8921 & 20708.24 & 48.50 & 1807.38 & 18.1210 & 22089.57 & 49.21 & 1891.29 & 17.6781 \\
\hline Average & 19350.78 & 100.00 & 1596.79 & 20.0044 & 19753.26 & 100.00 & 1917.10 & 19.1201 & 20800.01 & 100.00 & 1990.94 & 18.7193 \\
\hline
\end{tabular}

\section{Table 5B Distribution of Personal Outpatient Care Utilization}

\section{Classified by Sex}

\begin{tabular}{|c|c|c|c|c|c|c|c|c|c|c|c|c|}
\hline \multirow{3}{*}{ Sex } & & & & & & & & & & & Unit: NT\$ & $\%$ \\
\hline & \multicolumn{4}{|c|}{1999} & \multicolumn{4}{|c|}{2000} & \multicolumn{4}{|c|}{2001} \\
\hline & Expenditure & Percentage & Copayment & Times & Expenditure & Percentage & Copayment & Times & Expenditure & Percentage & Copayment & Times \\
\hline Women & 11458.83 & 52.43 & 1208.34 & 17.9514 & 11405.56 & 52.21 & 1353.47 & 17.0437 & 11865.18 & 52.28 & 1381.33 & 16.6167 \\
\hline Men & 11993.07 & 47.57 & 1005.88 & 16.4458 & 12129.09 & 47.79 & 1160.46 & 15.7358 & 12541.97 & 47.72 & 1190.61 & 15.2315 \\
\hline Average & 11706.90 & 100.00 & 1114.33 & 17.2523 & 11740.28 & 100.00 & 1264.18 & 16.4387 & 12178.77 & 100.00 & 1292.96 & 15.9748 \\
\hline
\end{tabular}




\section{Table 5C Distribution of Personal Inpatient Care Utilization}

\section{Classified by Sex}

\begin{tabular}{|c|c|c|c|c|c|c|c|c|c|c|c|c|}
\hline \multirow[b]{3}{*}{ Sex } & & & & & & & & & & & Unit: NT & $\Gamma \$, \%$ \\
\hline & \multicolumn{4}{|c|}{1999} & \multicolumn{4}{|c|}{2000} & \multicolumn{4}{|c|}{2001} \\
\hline & Days & Expenditure & Percentage & Copayment & Days & Expenditure & Percentage & Copayment & Days & Expenditure & Percentage & Copayment \\
\hline Women & 0.99074 & 4978.44 & 47.84 & 291.625 & 1.00562 & 5181.60 & 47.63 & 294.322 & 0.99667 & 5323.36 & 45.27 & 301.200 \\
\hline Men & 1.24519 & 6260.85 & 52.16 & 330.895 & 1.26345 & 6619.21 & 52.37 & 337.420 & 1.36570 & 7453.21 & 54.73 & 361.460 \\
\hline Average & 1.10889 & 5573.91 & 100.00 & 309.860 & 1.12490 & 5846.66 & 100.00 & 314.260 & 1.16766 & 6310.23 & 100.00 & 329.121 \\
\hline
\end{tabular}




\section{Table 6A Distribution of Personal Total Health Care Utilization}

\section{Classified by Region}

Unit: NT\$, \%

\begin{tabular}{|c|c|c|c|c|c|c|c|c|c|c|c|c|}
\hline \multirow{2}{*}{ Region } & \multicolumn{4}{|c|}{1999} & \multicolumn{4}{|c|}{2000} & \multicolumn{4}{|c|}{2001} \\
\hline & Expenditure & Percentage & Copayment & Times & Expenditure & Percentage & Copayment & Times & Expenditure 1 & Percentage & Copayment & Times \\
\hline North & 14350.68 & 33.27 & 1446.48 & 13.4170 & 14694.67 & 33.24 & 1446.48 & 13.4170 & 15087.39 & 32.96 & 1473.76 & 13.1298 \\
\hline Middle & 14831.54 & 18.90 & 1414.99 & 15.8898 & 15723.70 & 19.56 & 1414.99 & 15.8898 & 16201.48 & 19.46 & 1511.97 & 15.0050 \\
\hline M-South & 15615.96 & 16.26 & 1621.77 & 15.4604 & 15866.01 & 16.12 & 1621.77 & 15.4604 & 16723.99 & 16.41 & 1623.29 & 14.8995 \\
\hline South & 15253.21 & 16.64 & 1427.25 & 15.4516 & 15380.32 & 16.37 & 1427.25 & 15.4516 & 15989.64 & 16.44 & 1414.68 & 15.0280 \\
\hline Average & 14817.22 & 100.00 & 1457.92 & 14.5419 & 15184.96 & 100.00 & 1457.92 & 14.5419 & 15723.48 & 100.00 & 1490.26 & 14.0736 \\
\hline
\end{tabular}




\section{Table 6B Distribution of Personal Outpatient Care Utilization}

\section{Classified by Region}

\begin{tabular}{|c|c|c|c|c|c|c|c|c|c|c|c|c|}
\hline \multicolumn{13}{|c|}{ Unit: NT\$, \% } \\
\hline \multirow{2}{*}{ Region } & \multicolumn{4}{|c|}{1999} & \multicolumn{4}{|c|}{2000} & \multicolumn{4}{|c|}{2001} \\
\hline & Expenditure & Percentage & Copayment & Times & Expenditure & Percentage & Copayment & Times & Expenditure I & Percentage & Copayment & Times \\
\hline M-North & 7911.22 & 11.81 & 725.41 & 11.8117 & 8100.23 & 11.99 & 859.03 & 11.4521 & 8121.19 & 11.80 & 864.430 & 11.0820 \\
\hline Middle & 8470.75 & 18.85 & 792.70 & 12.9288 & 8683.39 & 19.16 & 917.68 & 12.7843 & 8811.02 & 19.10 & 963.023 & 11.9447 \\
\hline M-South & 9222.80 & 16.77 & 1000.06 & 14.3064 & 9188.76 & 16.57 & 1017.86 & 13.1346 & 9394.83 & 16.64 & 998.848 & 12.5220 \\
\hline East & 8699.52 & 2.57 & 778.54 & 12.5190 & 8513.55 & 2.49 & 932.31 & 12.0344 & 8864.94 & 2.55 & 942.936 & 11.7663 \\
\hline Average & 8484.69 & 100.00 & 821.93 & 12.7117 & 8557.86 & 100.00 & 931.97 & 12.1673 & 8713.14 & 100.00 & 938.044 & 11.6646 \\
\hline
\end{tabular}




\section{Table 6C Distribution of Personal Inpatient Care Utilization}

\section{Classified by Region}

\begin{tabular}{|c|c|c|c|c|c|c|c|c|c|c|c|c|}
\hline \multirow{3}{*}{ Region } & \multirow{2}{*}{\multicolumn{4}{|c|}{1999}} & \multirow{2}{*}{\multicolumn{4}{|c|}{2000}} & \multicolumn{4}{|c|}{ Unit: NT\$, \% } \\
\hline & & & & & & & & & & 200 & & \\
\hline & Expenditure & Percentage & Copayment & Days & Expenditure & Percentage & Copayment & Days & Expenditure & Percentage & Copayment & Days \\
\hline M-North & 4563.54 & 12.84 & 245.917 & 0.91823 & 4609.61 & 12.42 & 243.968 & 0.92420 & 4970.09 & 13.64 & 246.561 & 0.93649 \\
\hline Middle & 4188.55 & 17.57 & 217.330 & 0.80779 & 4708.94 & 18.92 & 218.689 & 0.87411 & 4998.69 & 18.96 & 244.276 & 0.90884 \\
\hline East & 7064.66 & 3.94 & 348.363 & 1.41803 & 6526.73 & 3.48 & 364.057 & 1.39927 & 6961.67 & 3.51 & 366.201 & 1.48275 \\
\hline Average & 4501.99 & 100.00 & 248.341 & 0.89281 & 4700.92 & 100.00 & 248.084 & 0.89852 & 4979.87 & 100.00 & 256.240 & 0.91846 \\
\hline
\end{tabular}




\section{Table 7A Distribution of Personal Total Health Care Utilization}

\section{Classified by Rurality}

Unit: NT\$, \%

\begin{tabular}{|c|c|c|c|c|c|c|c|c|c|c|c|c|}
\hline \multirow{2}{*}{$\begin{array}{c}\text { Remote } \\
\text { Area }\end{array}$} & \multicolumn{4}{|c|}{1999} & \multicolumn{4}{|c|}{2000} & \multicolumn{4}{|c|}{2001} \\
\hline & Expenditure & Percentage & Copayment & Times & Expenditure & Percentage & Copayment & Times & Expenditure & Percentage & Copayment & Times \\
\hline No & 16320.46 & 98.31 & 1362.25 & 16.8085 & 16719.40 & 98.15 & 1633.78 & 16.1979 & 17374.64 & 98.01 & 1678.84 & 15.7457 \\
\hline Yes & 18617.25 & 1.69 & 1036.21 & 21.6713 & 18956.13 & 1.85 & 1339.39 & 21.3083 & 19011.15 & 1.99 & 1330.84 & 20.3404 \\
\hline Average & 16354.49 & 100.00 & 1357.42 & 16.8806 & 16755.89 & 100.00 & 1628.98 & 16.2812 & 17404.40 & 100.00 & 1672.51 & 15.8293 \\
\hline
\end{tabular}

\section{Table 7B Distribution of Personal Outpatient Care Utilization}

\section{Classified by Rurality}

Unit: NT\$, \%

\begin{tabular}{|c|c|c|c|c|c|c|c|c|c|c|c|c|}
\hline \multirow{2}{*}{$\begin{array}{c}\text { Remote } \\
\text { Area }\end{array}$} & \multicolumn{4}{|c|}{1999} & \multicolumn{4}{|c|}{2000} & \multicolumn{4}{|c|}{2001} \\
\hline & Expenditure & Percentage & Copayment & Times & Expenditure & Percentage & Copayment & Times & Expenditure & Percentage & Copayment & Times \\
\hline No & 9509.88 & \begin{tabular}{|l|l|}
98.27 \\
\end{tabular} & \begin{tabular}{|r|}
928.95 \\
\end{tabular} & 14.2134 & 9617.40 & 98.11 & 1055.54 & 13.6316 & 9835.92 & 97.95 & 1068.90 & 13.1225 \\
\hline Yes & 11121.01 & 1.73 & 594.15 & 19.7202 & 11195.41 & 1.89 & 752.96 & 19.3126 & 11111.78 & 2.05 & 735.20 & 18.3245 \\
\hline Average & 9533.74 & 100.00 & 923.99 & 14.2950 & 9643.15 & 100.00 & 1050.61 & 13.7242 & 9859.12 & 100.00 & 1062.83 & 13.2171 \\
\hline
\end{tabular}




\section{Table 7C Distribution of Personal Inpatient Care Utilization}

\section{Classified by Rurality}

\begin{tabular}{|c|c|c|c|c|c|c|c|c|c|c|c|c|}
\hline \multirow[b]{3}{*}{$\begin{array}{c}\text { Remote } \\
\text { Area }\end{array}$} & & & & & & & & & & & Unit: $\mathbf{N}$ & $\mathrm{TS}, \%$ \\
\hline & \multicolumn{4}{|c|}{1999} & \multicolumn{4}{|c|}{2000} & \multicolumn{4}{|c|}{2001} \\
\hline & Days & Expenditure & Percentage & Copayment & Days & Expenditure & Percentage & Copayment & Days & Expenditure & Percentage & Copayment \\
\hline No & 0.96418 & 4855.73 & 98.19 & 271.817 & 0.95946 & 5028.83 & 98.03 & 272.360 & 0.98465 & 5334.74 & 97.90 & 281.694 \\
\hline Yes & 1.38790 & 5947.68 & 1.81 & 358.718 & 1.36908 & 6080.08 & 1.97 & 387.163 & 1.43507 & 6169.42 & 2.10 & 375.342 \\
\hline Average & 0.97045 & 4871.91 & 100.00 & 273.104 & 0.96614 & 5045.98 & 100.00 & 274.233 & 0.99284 & 5349.92 & 100.00 & 283.397 \\
\hline
\end{tabular}




\section{Table 8A Distribution of Personal Total Health Care Utilization}

\section{Classified by Catastrophic Disease}

\begin{tabular}{|c|c|c|c|c|c|c|c|c|c|c|c|c|}
\hline \multirow{2}{*}{$\begin{array}{c}\text { Having } \\
\text { Catastrophic } \\
\text { Disease }\end{array}$} & & \multicolumn{2}{|c|}{1999} & & \multicolumn{3}{|c|}{2000} & & & 2001 & Unit: $\mathbf{N}$ & T\$, $\%$ \\
\hline & Expenditure & Percentage & Copayment & Times & Expenditure & Percentage & Copayment & Times & Expenditure & Percentage & Copayment & Times \\
\hline No & 13416.31 & 80.39 & 1330.56 & 16.5418 & 13601.20 & 79.46 & 1599.07 & 15.9551 & 13915.59 & 78.15 & 1641.50 & 15.4700 \\
\hline Yes & 160259.94 & 19.61 & 2673.00 & 33.4855 & 163419.08 & 20.54 & 3019.36 & 31.4469 & 168483.70 & 21.85 & 3015.26 & 31.3924 \\
\hline Average & 16354.49 & 100.00 & 1357.42 & 16.8806 & 16755.89 & 100.00 & 1628.98 & 16.2812 & 17404.40 & 100.00 & 1672.51 & 15.8293 \\
\hline
\end{tabular}

\section{Table 8B Distribution of Personal Outpatient Care Utilization}

\section{Classified by Catastrophic Disease}

\begin{tabular}{|c|c|c|c|c|c|c|c|c|c|c|c|c|}
\hline \multicolumn{13}{|c|}{ Unit: NT\$, \% } \\
\hline \multirow{2}{*}{$\begin{array}{c}\text { Having } \\
\text { Catastrophic } \\
\text { Disease }\end{array}$} & \multicolumn{4}{|c|}{1999} & \multicolumn{4}{|c|}{2000} & \multicolumn{4}{|c|}{2001} \\
\hline & Expenditure & Percentage & Copayment & Times & Expenditure & Percentage & Copayment & Times & Expenditure & Percentage & Copayment & Times \\
\hline No & 7905.60 & 81.26 & 915.20 & 13.9617 & 7820.43 & 79.39 & 1039.11 & 13.4008 & 7847.35 & 77.80 & 1051.18 & 12.8624 \\
\hline Yes & 89276.31 & 18.74 & 1354.40 & 30.6209 & 94382.40 & 20.61 & 1584.99 & 28.7626 & 96977.02 & 22.20 & 1567.39 & 28.5809 \\
\hline Average & 9533.74 & 100.00 & 923.99 & 14.2950 & 9643.15 & 100.00 & 1050.61 & 13.7242 & 9859.12 & 100.00 & 1062.83 & 13.2171 \\
\hline
\end{tabular}




\section{Table 8C Distribution of Personal Inpatient Care Utilization}

\section{Classified by Catastrophic Disease}

\begin{tabular}{|c|c|c|c|c|c|c|c|c|c|c|c|c|}
\hline \multirow{2}{*}{$\begin{array}{c}\text { Having } \\
\text { Catastrophic } \\
\text { Disease }\end{array}$} & & & & & & & & & & & Unit: & NTS, \% \\
\hline & Days & Expenditure & Percentage & Copayment & Days & Expenditure & Percentage & Copayment & Days & Expenditure & Percentage & Copayment \\
\hline No & 0.7199 & 3565.99 & 71.73 & 255.13 & 0.7169 & 3716.92 & 72.11 & 257.45 & 0.7207 & 3876.48 & 70.82 & 265.24 \\
\hline Yes & 13.2437 & 68833.05 & 28.27 & 1153.36 & 12.5556 & 66834.62 & 27.89 & 1054.27 & 12.7777 & 69155.69 & 29.18 & 1069.81 \\
\hline Average & 0.9705 & 4871.91 & 100.00 & 273.10 & 0.9661 & 5045.98 & 100.00 & 274.23 & 0.9928 & 5349.92 & 100.00 & 283.40 \\
\hline
\end{tabular}


Table 9 The Distribution of Catastrophic Disease Incidence

\section{Ranked by Equivalent Income Decile}

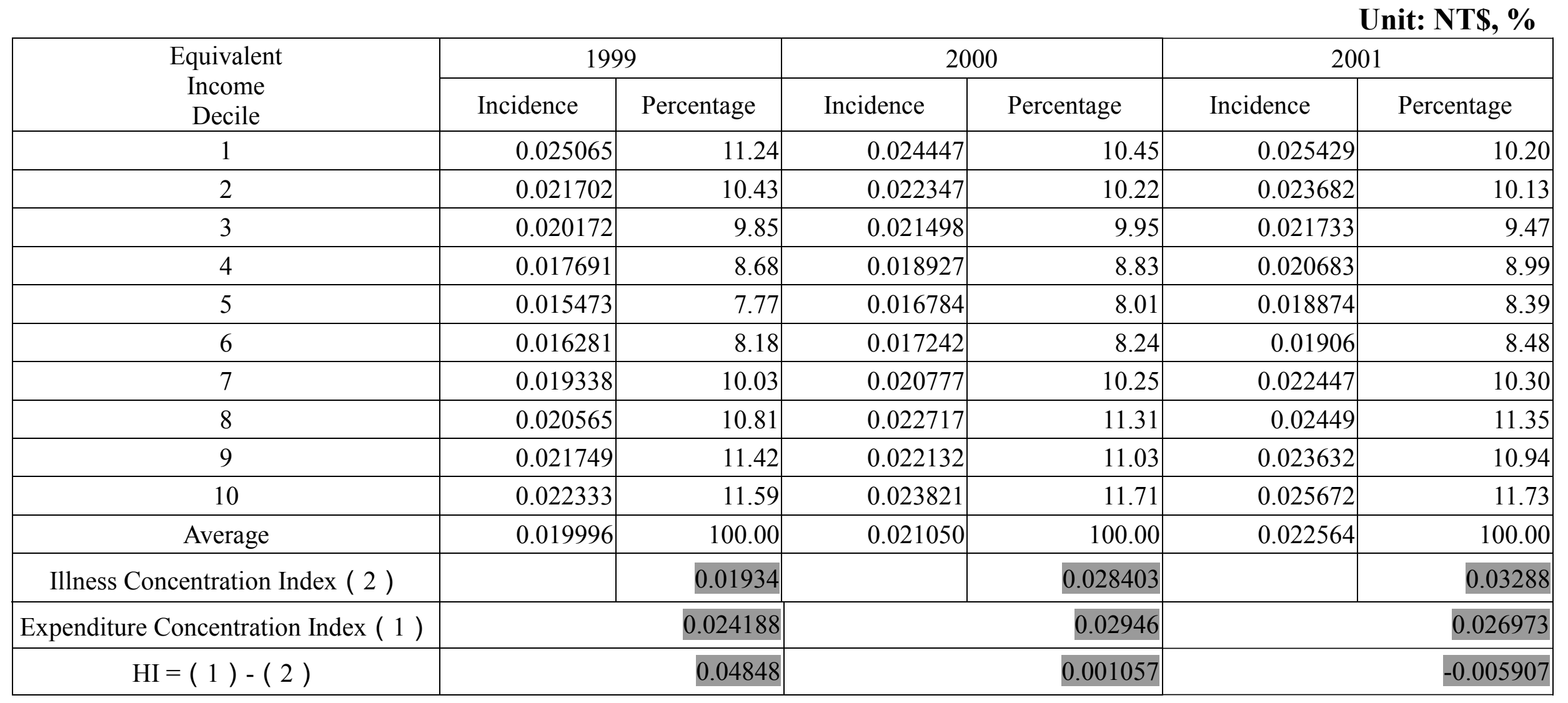




\section{Table 10 Cross-national Comparison of the Equity}

In Health Care Delivery

\begin{tabular}{|c|c|c|c|c|c|c|c|c|c|}
\hline \multirow{2}{*}{$(1)^{1}$} & Country & Italy & Netherlands & U.K. & Taiwan $^{2}$ & & & & \\
\hline & HI & 0.118 & 0.038 & 0.014 & -0.006 & & & & \\
\hline \multirow[b]{2}{*}{ ( 2 ) } & Country & Spain & Australia & U.S. & U.K. & Denmar & & & \\
\hline & HI & 2.000 & 0.060 & 0.018 & 0.000 & -0.100 & & & \\
\hline \multirow{2}{*}{ ( 3 ) } & Country & Spain & U.S. & Netherlands & U.K. & Italy & Switzerland & Denmark & Ireland \\
\hline & $\mathrm{HI}$ & 0.146 & 0.028 & 0.025 & 0.013 & -0.036 & -0.043 & -0.055 & -0.076 \\
\hline
\end{tabular}

Source: Panel (1) cited from Wagstaff et al (1994); Panel (2) cited from Lairson et al (1995);

Panel (3) cited from Wagstaff and van Doorshaer (1993).

Note: 1. In Panel (1), HI= $\mathrm{C}^{\text {EXP }}-\mathrm{C}^{\text {ill }}$; and in Panel (2) and (3) $\mathrm{HI}$ is standardized concentration index of medical expenditure, using health risk factors as adjustment. 
2. The HI value of Taiwan is based on the 2001 data analyzed in this study. 